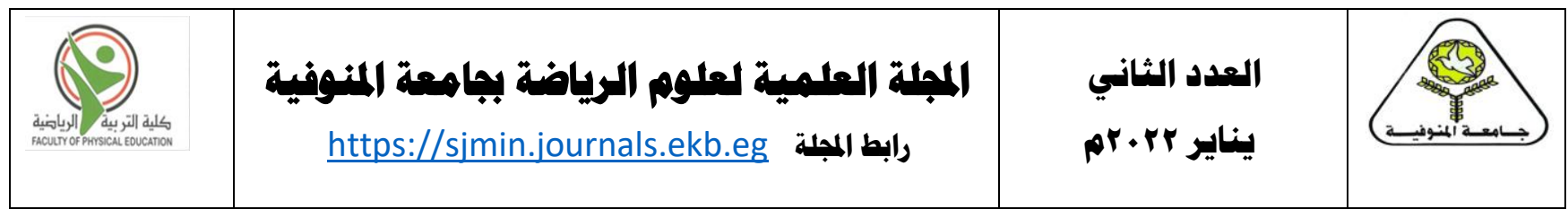

" الإمكانات المدرسية (المادية -البثرية) المتاحة لنثر ثقافة الرياضة لاي تلاميذ مرحلة

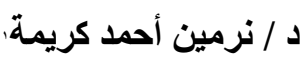

التعليم الأساسي للصم البكم"

دمد / شيريهان يحيب مرئ مرسي.

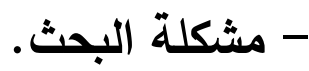

لا شك أن الإعلام يلعب دورا حيويا في تقدم الثعوب وانحطاطها، ويقاس مدي تحضر الدول

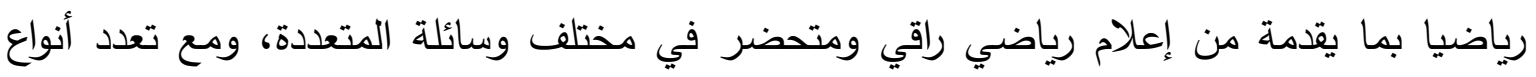
الإعلام الرياضي بين المسموع والمقرؤه والإلكتروني والمرئي وغير المرئي وتئي ونتعدد الأدوار والمهام علي

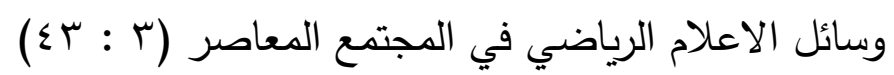

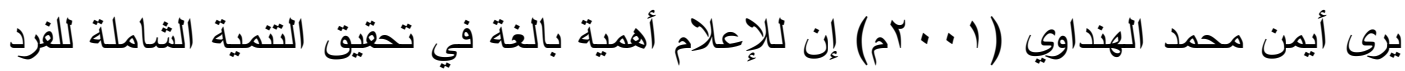

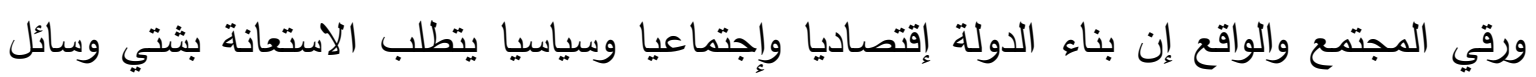

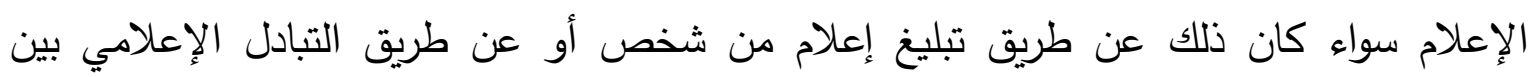

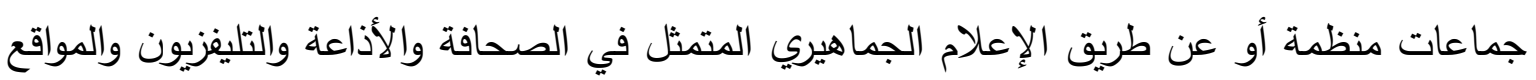

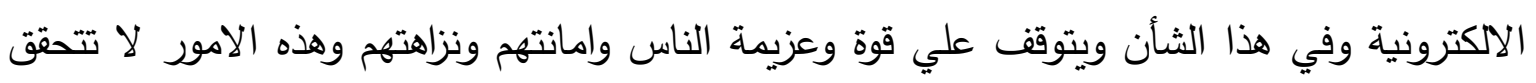

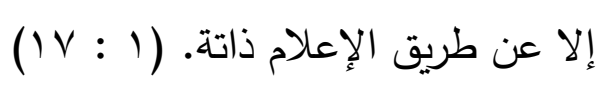

ويعتبر الإعلام المدرسي أحد المحاور الرئيسية والمهمة في بناء شخصية الطلاب وعلية فإذا

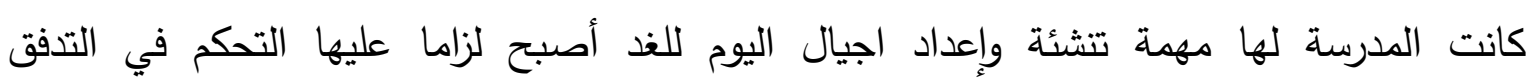

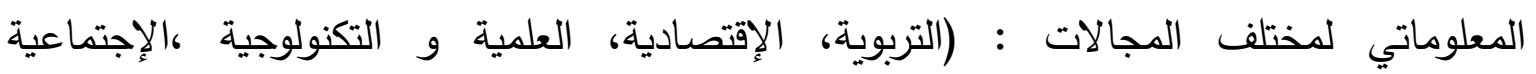

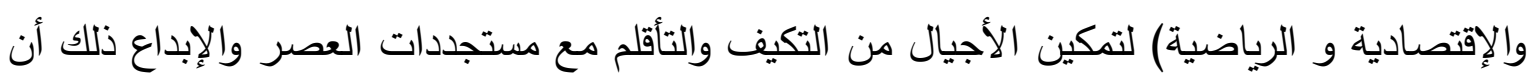

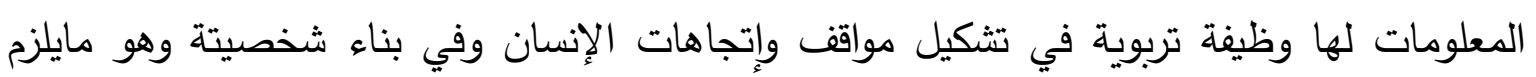

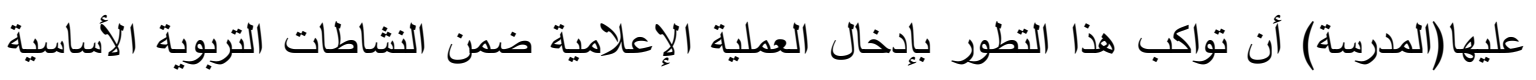

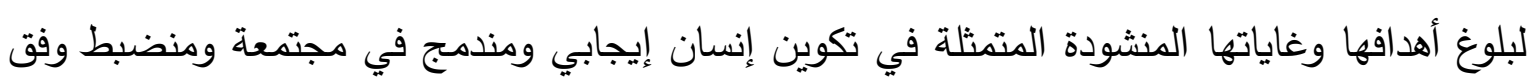

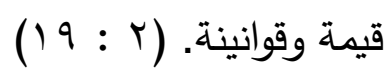

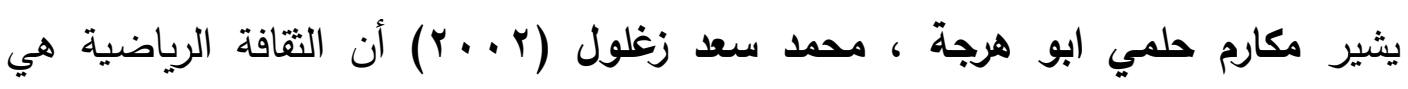

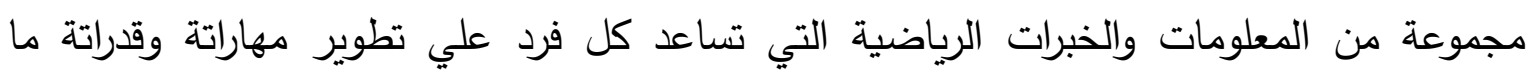


يمارسة من أنثطة رياضية ، كما تعد الثقافة الرياضية من أهم أهداف برامج التربية الرياضية فلا غني

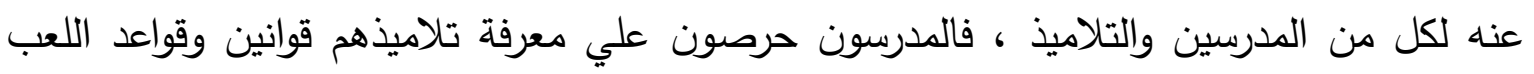

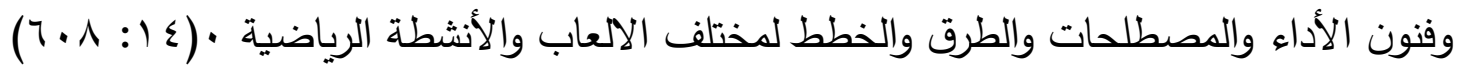

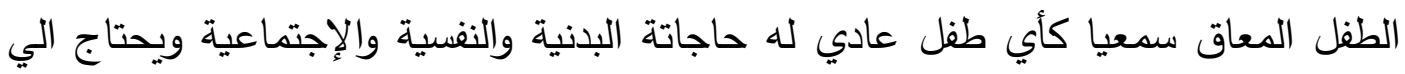

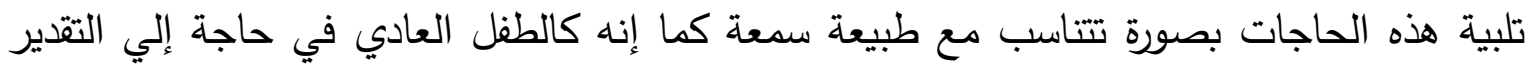

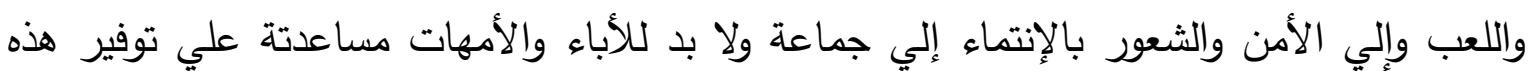
الإحتياجات بالطرق المنا سبة بما يعمل علي نمو شخصية الطفل الأصم الأبكم نموا صحيحاً.

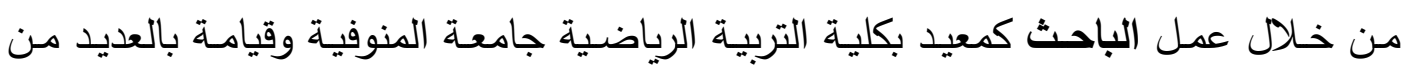

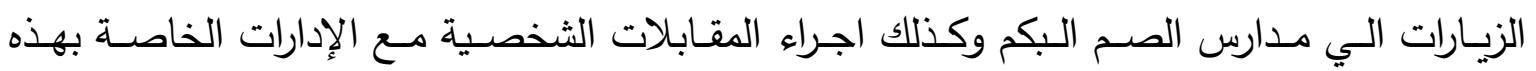

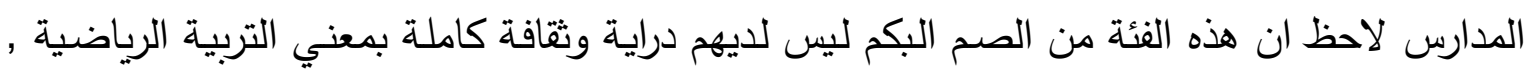

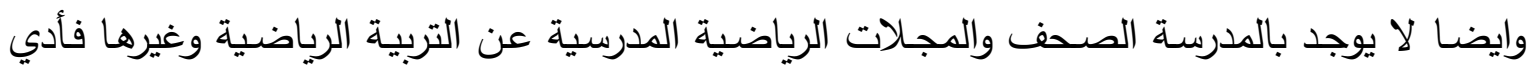

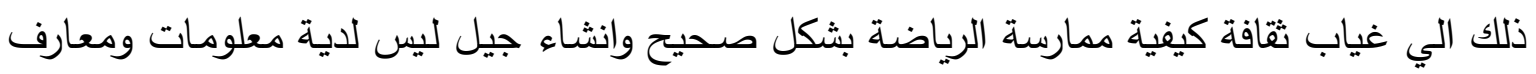

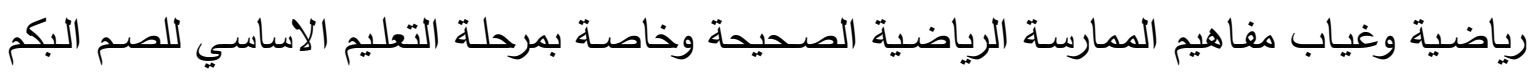

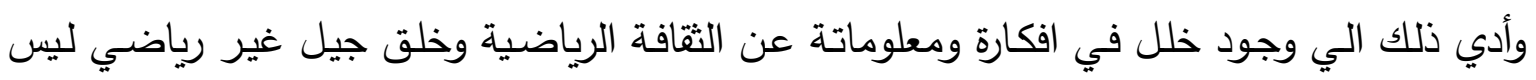

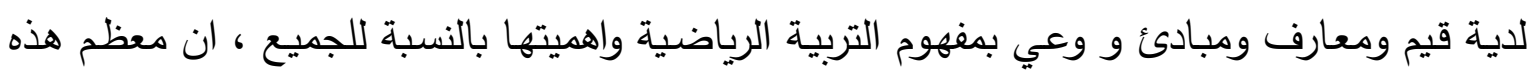

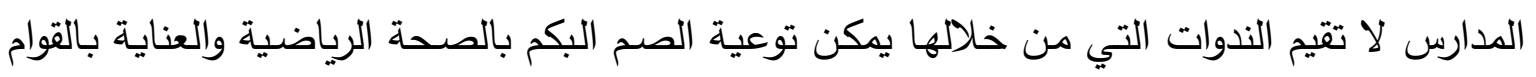
والعناية بأجسامهم وكذلك لا تستعين هذه المدارس بالاعلام الرياضي المرئي في تثقيف هذه الفئة من

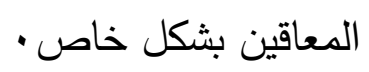
وفي حدود علم الباحث يري ان هذا البحث محاولة جادة منة لتعزيز قيمة الثقافة الرياضية في مدراس الصم البكم وإرساء قواعد سليمة للممارسة الرياضية.

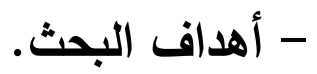
توظيف الإمكانات المدرسية (المادية - البشرية )المتاحة لنشر ثقافة الرياضـة لدي تلاميذ

• مرحلة التعليم الاساسي للصم البكم

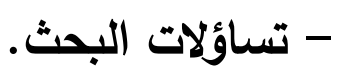
1-ماهي الإمكانات المادية المتاحة لنشر ثقافة الرياضة لاي تلاميذ مرحلة التعليم الاساسي للصم البكم ؟ 
ץ- ماهي الإمكانات البشرية المتاحة لنشر ثقافة الرياضة لدي تلاميذ مرحلة التعليم

$$
\text { - منراء ات البحث. البحثي للصم البكم ؟ }
$$

إستخدم الباحثون المنهج الوصفي بإستخدام الدراسات المسحية كأحد انماطة وذلك لملائمتة

$$
\begin{aligned}
& \text { لطبيعة البحث واهدافة. } \\
& \text { - مجتمع وعينة البحث. } \\
& \text { - مجتمع البحث. }
\end{aligned}
$$

يمثل مجتمع البحث مديري المدارس و موجهي التربية الرياضية و مدرسي التربية الرياضة

$$
\text { - لمدارس التعليم الأساسي للصم البكم. }
$$

اختار الباحثون عينة البحث بالطريقة العمدية وعددها (• (م) مفحوصاً من مديري المدارس وموجهي التربية الرياضية ومدرسي التربية الرياضية للصم البكم بمحافظة المنوفية وتم تقسيمهم إلي ( • ( ) مفحوصا لإجراء الدراسة الاستطلاعية و(·) لحساب المعاملات العلمية ( الصدق والثبات ) و( • ع) مفحوصاً كعينة أساسية لإجراء التطبيق النهائي. - أدوات جمع البيانات. قام الباحثون بإعداد الإستبيان وإتبع الباحثون الخطوات التالية في إعداد الإستبيان : • القراءات النظرية للمراجع العلمية والدراسات المرتبطة بموضوع الدراسة ل المقابلة الشخصية . - تحديد محاور الإستبيان

• عرض المحاور علي السادة الخبراء تم التوصل الي الصورة النهائية للمحاور ل

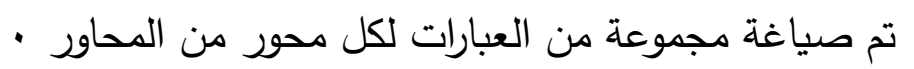
• عرض مجموعة العبارات لكل محور علي السادة الخبراء • صياغة الصورة النهائية للإستبيان 
- المعاملات العلمية للإستبيان.

- صدق الإستبيان.

قام الباحثون بحساب معامل صدق الإستبيان الخاص بدور الأعلام الرياضي الددرسي في

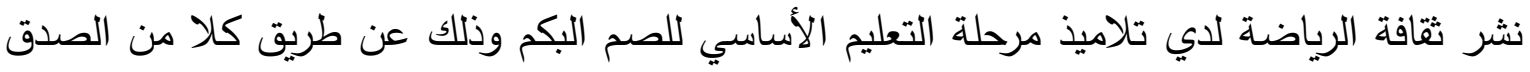

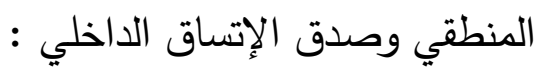
- الصدق المنطقي للإستبيان. إستخدم الباحثون الصدق المنطقي بعرض الإستبيان علي عدد (• (1) من الخبراء من أعضاء

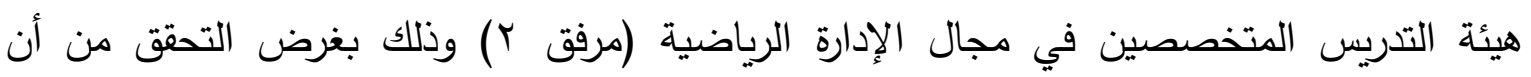

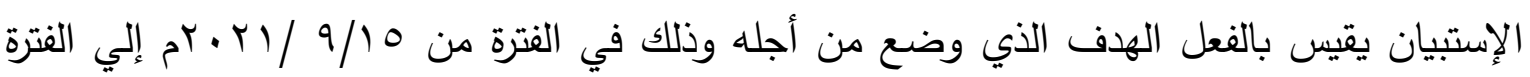

$$
\begin{aligned}
& \text { مr. r / / q/rq } \\
& \text { وإتبع الباحث الخطوات التالية :- }
\end{aligned}
$$

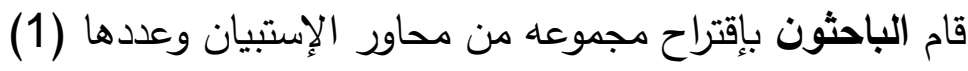

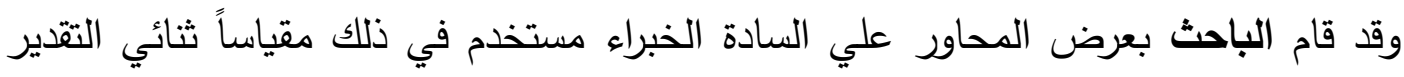

$$
\begin{aligned}
& \text { (مناسب - غير مناسب ) وكانت شروط إختيار الخبير أن يكون علي النحو التالي : }
\end{aligned}
$$

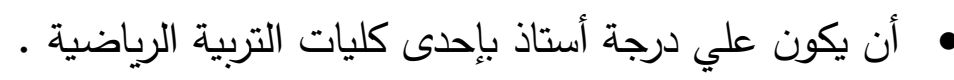

$$
\begin{aligned}
& \text { • ان يكون متخصص في مجال الإدارة الرياضية . } \\
& \text { وجاء رأي السادة الخبراء حول مناسبة محاور الإستبيان كما يلي : }
\end{aligned}
$$

\begin{tabular}{|c|c|c|c|c|c|c|c|}
\hline \multirow{2}{*}{ النسبية } & \multirow{2}{*}{ النسبي } & \multicolumn{2}{|c|}{ غيرموافق } & \multicolumn{2}{|c|}{ موافق } & \multirow{2}{*}{ 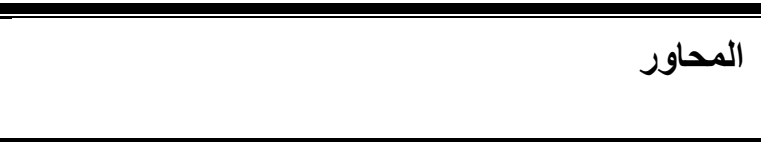 } & \multirow{2}{*}{ p } \\
\hline & & $\%$ & S & $\%$ & s & & \\
\hline$\overline{\lambda \cdot, . .}$ & ᄉ & $r_{r \cdot, \ldots}$ & r r & $\bar{\lambda} \Lambda_{\cdot}, \ldots$ & $\overline{1} \wedge$ & الإمكانات الخاصة المدرسية وتشمل (البشرية ـ المادية ) & 1 \\
\hline
\end{tabular}

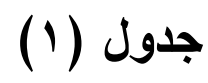

آراء السادة الخبراء حول محاور إستبيان ن=.

يوضح جدول (1) التكرار والنسبة المئوية والوزن النسبي والأهمية النسبية لأراء السادة الخبراء

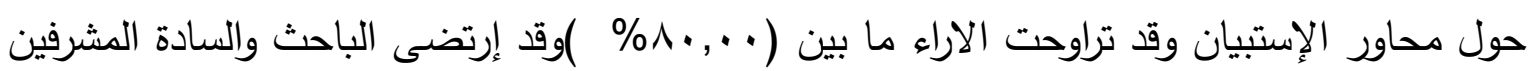

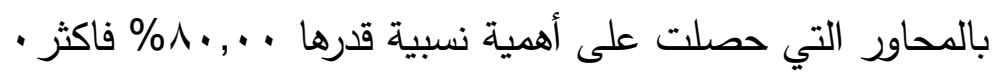


ثم قام الباحثون بصياغة مجموعة من العبارات لكل محور حيث بلغ عدد عبارات الإستبيان

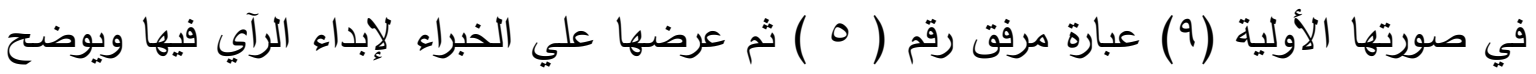

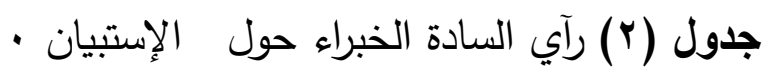

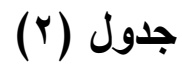

النسبة المئوية لأراء السادة الخبراء حول عبارات استمارة استبيان ن=.”

\begin{tabular}{|c|c|}
\hline المحور الأول & \\
\hline نسبة الموافقة \% & $\bar{~}$ \\
\hline 90.00 & 1 \\
\hline 100.00 & 2 \\
\hline 70.00 & 3 \\
\hline 100.00 & 4 \\
\hline 100.00 & 5 \\
\hline 100.00 & 6 \\
\hline 90.00 & 7 \\
\hline 80.00 & 8 \\
\hline 100.00 & 9 \\
\hline
\end{tabular}

يوضح جدول ( r ) النسبة المئوية لأراء السادة الخبراء حول عبارات الاستبيان ويتضح

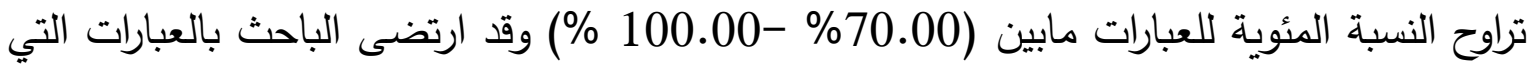
حصلت على اهمية نسبية قدرها $70.00 \%$

$$
\text { جدول (r) }
$$

العدد المبئي والنهائي وأرقام العبارات المستبعدة لإستمارة إستبيان

\begin{tabular}{|c|c|c|c|c|c|c|c|}
\hline للعبار العائي & أرقام العبارات & المعدلة العبار & أرقام العبارات & علد العبارات & للعبارات المبئي & المحاور & r \\
\hline 9 & - & - & - & - & 9 & الاول & 1 \\
\hline 9 & $\varepsilon$ & - & - & - & 9 & المجموع & \\
\hline
\end{tabular}

يوضح جدول (r) العدد المبدئي والنهائي وأرقام العبارات المستبعدة لإستمارة الإستبيان

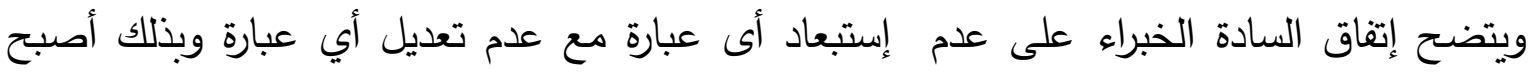

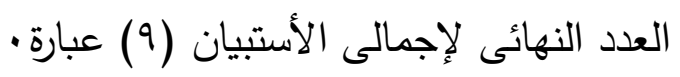




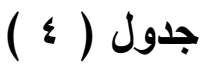

صدق الاتساق الداخلى بين العبارة والمحور وبين العبارة والمجموع

الكلى لمحاور استمارة ن = 20

\begin{tabular}{|c|c|c|}
\hline \multicolumn{3}{|c|}{ المحور الأول } \\
\hline العبارة مع المجموع & البحدور مع & s \\
\hline 0.85 & 0.91 & 1 \\
\hline 0.78 & 0.86 & 2 \\
\hline 0.83 & 0.87 & 3 \\
\hline$\cdot, \Lambda 4$ & $\cdot, 9 Y$ & 4 \\
\hline 0.91 & 0.85 & 5 \\
\hline 0.84 & 0.90 & 6 \\
\hline$\cdot, \sqrt{ } 9$ & $\cdot, \wedge \wedge$ & 7 \\
\hline$\cdot, \mathrm{V}_{0}$ & $\cdot, \mathrm{V} \wedge$ & 8 \\
\hline 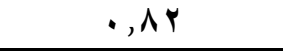 & $\cdot, 91$ & 9 \\
\hline
\end{tabular}

قيمةًر الجدولية عند مستوى معنوية

يوضح جدول (0) وجود إرتباط ذو دلالة إحصائية بين العبارة والمحور حيث تراوحت

قيمة ( ر) المحسوبة ما بين(10.7 - r0.90) وكنلك وجود إرتباط ذو دلالة إحصائية بين

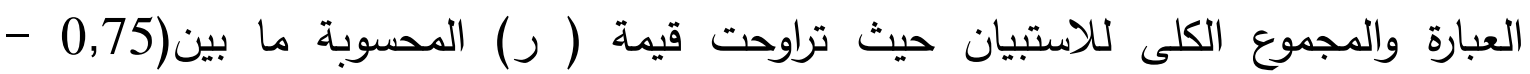
ال10.9)وذلك عند مستوى معنوية 0.05 مما يشير إلى صدق الإتساق الداخلى للاستبيان قيد البحث

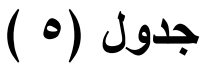

صدق الاتساق الداخلى بين المحور والمجموع الكلى للمحاور لاستمارة استبيان ن= 20

\begin{tabular}{|c|c|c|}
\hline معامل الارتباط & 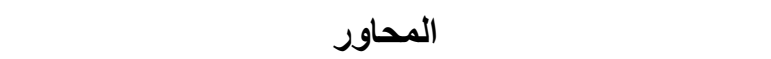 & م \\
\hline 0.923 & الإمكانات الخاصة المدرسية وتثثمل (البشرية _ المادية ) & 1 \\
\hline
\end{tabular}

يوضح جدول (0)وجود ارتباط ذو دلالة إحصائية بين مجموع المحور وبين المجموع الكلى لاستمارة استبيان حيث تراوحت قيمة ( ر) المحسوبة ما بين(0.923) ذلك عند مستوى معنوية 


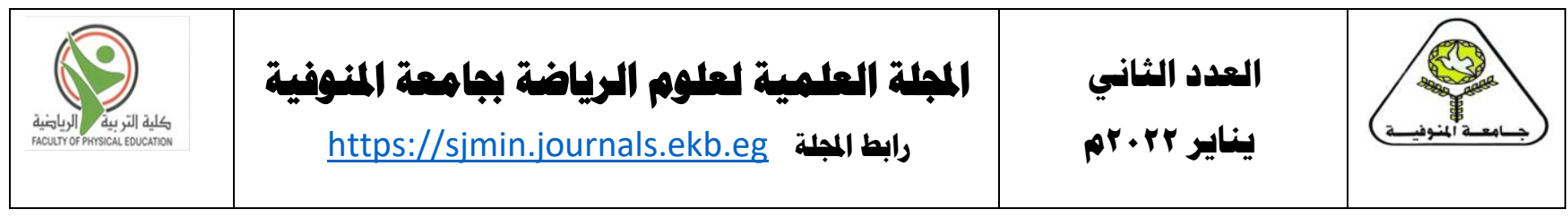

\section{جدول (7 )}

معامل الفا (كرونباخ) لبيان معامل الثبات لمحاور استمارة استبيان ن= دول 20

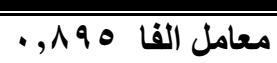

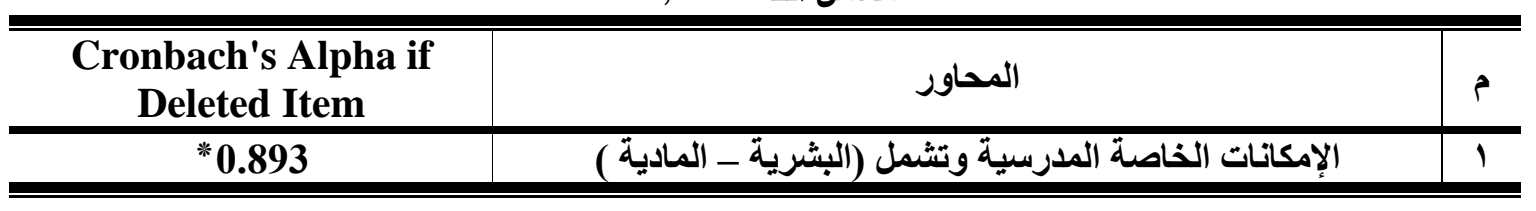

يوضح جدول (T) معامل الفا (كرونباخ) لبيان معامل الثبات لمحاور استمارة ويتضـح دلالة معامل الفا لمحاور البحث

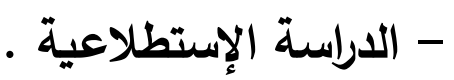
قام الباحثون بإجراء دراسة إستطلاعية علي عينة قوامها ( • ( ) مفحوصاً ممثلة من مجتمع البحث من مجموعة من مديرين وموجهين ومدرسين التربية الرياضية بمدارس الصم البكم بمحافظة

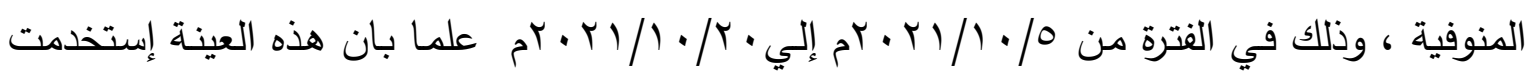

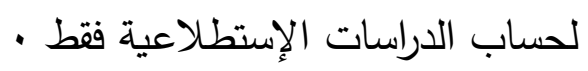
وكان الهدف من هذه الدراسة ما يلي :

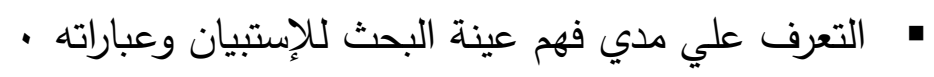
• التعرف علي الصعوبات المحتملة أثناء تطبيق الإستبيان -

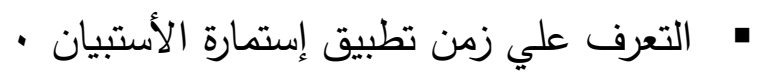
وقد أسفرت نتائج الدراسة الاستطلاعية كما يلي : • همح عينة البحث للإستبيان وعباراته -

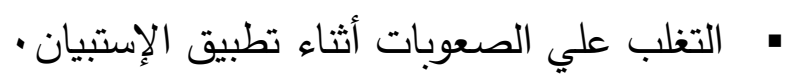
- الدراسات الإستطلاعية إستمارة الإستبيان. - تطبيق الاستبيان. بعد التأكد من توافر كافة الثروط العلمية والإداريـة لإستمارة الإستبيان لجميع آراءالعينـة قام الباحثون بتطبيق إستمارة الإستبيان علي مجموعة من مديرين ومدرسين وموجهين التربية الرياضية

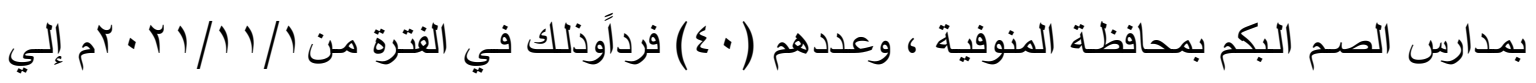
11/1/1 0

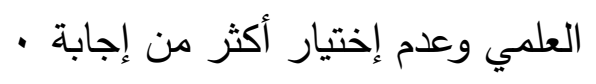




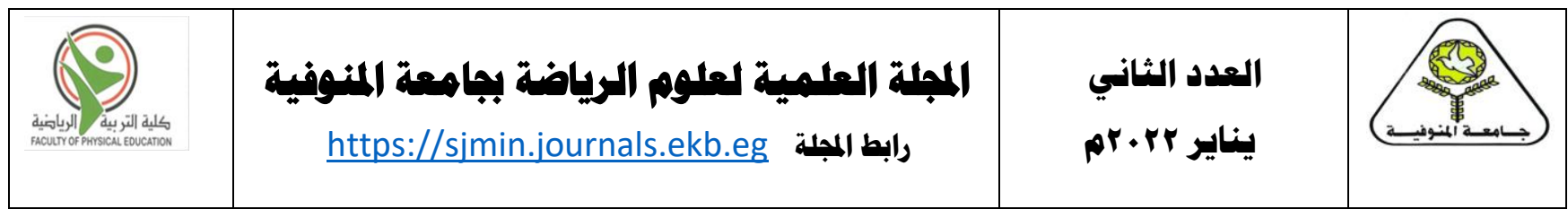

- المعالجات الإحصائية. إستخدم الباحثون المعالجة الإحصـائية الملائمة لطبيعة البحث ، وذلك من خلال

البرنامج الإحصائي spss وكانت كالتالي :

•

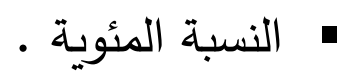

ـ الأهمية النسبية .

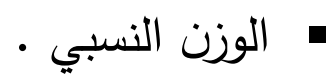

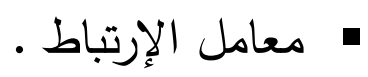

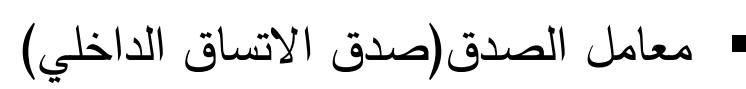

• معامل الثبات (إعادة التطبيق ).

• - ل اختباركا'.

• معامل ألفا ( كرو نباخ ) . 
- عرض ومناقشة النتائج -

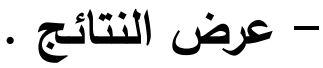

\section{جدول (· )}

آراء عينة البحث في المحور الخاص بالإمكانات المدرسية المتاحة وتشمل (المادية - البشرية ) لنشر ثقافة

الرياضة لاي تلاميذ مرحلة التعليم الاساسي للصم البكم ن=. ؟

\begin{tabular}{|c|c|c|c|c|c|c|c|c|c|c|}
\hline & الأهمية & الوزن & & $y$ & لد ما & إلى : & & نعم & \multirow[b]{2}{*}{ العبارة } & \\
\hline كا & النسبية & النسبي & $\%$ & ك5 & $\%$ & ك & $\%$ & ك & & 5 \\
\hline 351.45 & 000.45 & 54 & 50.82 & 33 & 00.0 & 0 & 50.17 & 7 & 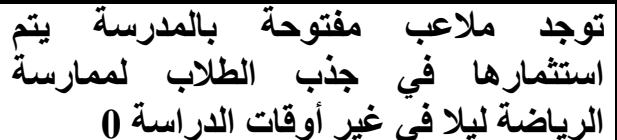 & \\
\hline 751.53 & 833.95 & 115 & 00.0 & 0 & 50.12 & 0 & 50.87 & ro & 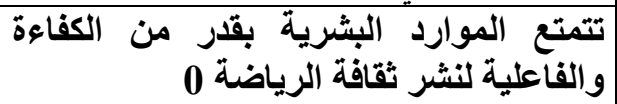 & r \\
\hline 600.8 & 000.65 & 78 & 00.25 & 1. & 00.55 & Tr & 00.20 & $\Lambda$ & 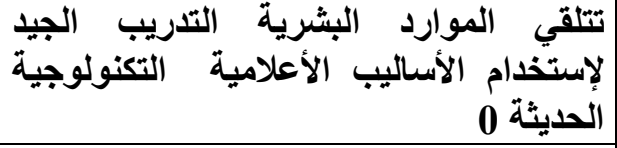 & $r$ \\
\hline 851.43 & 167.69 & 83 & 00.5 & r & 50.82 & Tr & 50.12 & 0 & 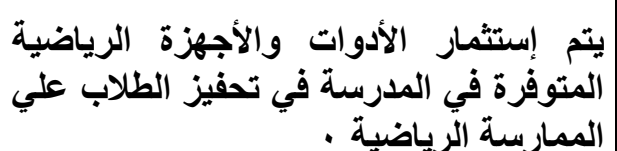 & \\
\hline 550.13 & 167.74 & 89 & 00.10 & $\varepsilon$ & 50.57 & Tr & 50.32 & $1 \pi$ & 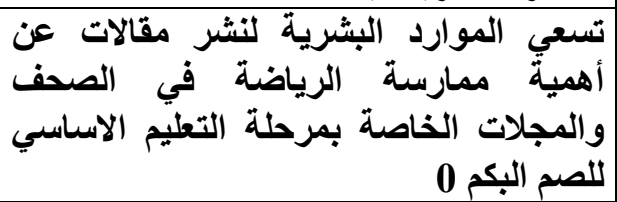 & \\
\hline 602.68 & 667.36 & 44 & 00.95 & 38 & 00.0 & 0 & 00.5 & 2 & 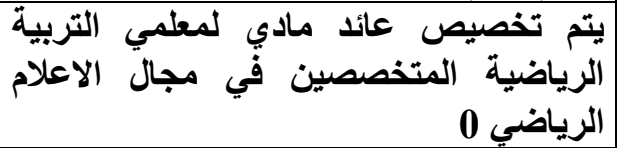 & 7 \\
\hline 951.21 & 833.85 & 103 & 00.10 & $\varepsilon$ & 50.22 & 9 & 50.67 & TV & 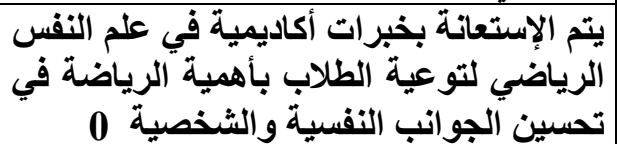 & V \\
\hline 550.13 & 167.74 & 89 & 00.10 & $\varepsilon$ & 50.57 & rT & 50.32 & $1 \pi$ & 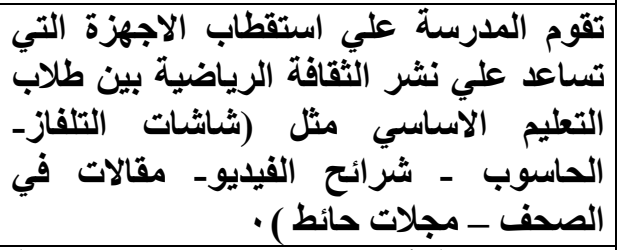 & $\wedge$ \\
\hline 351.45 & 167.94 & 113 & 00.0 & 0 & 50.17 & V & 50.82 & 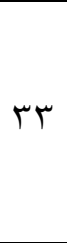 & 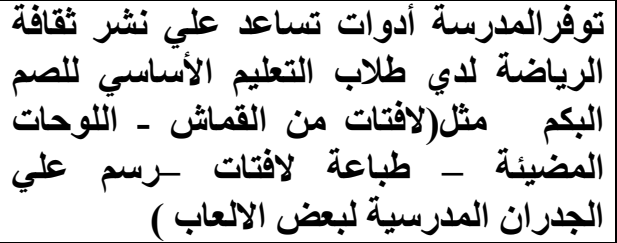 & 9 \\
\hline
\end{tabular}




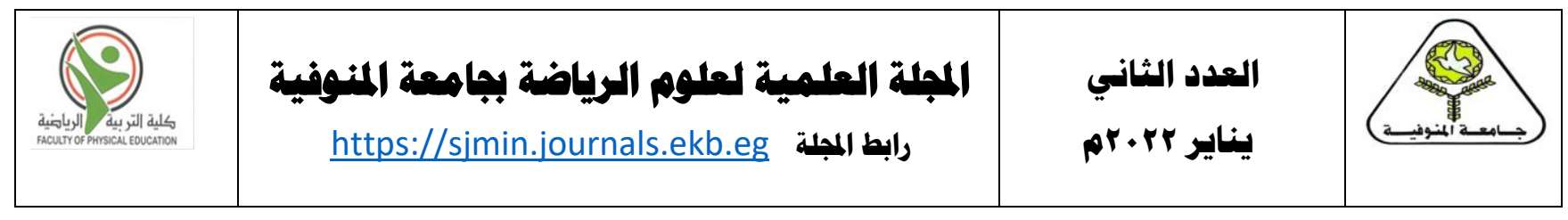

يتضح من جدول (· ( ) أن هناك فروق دالة إحصائية لآراء عينة البحث في جميع عبارات المحور

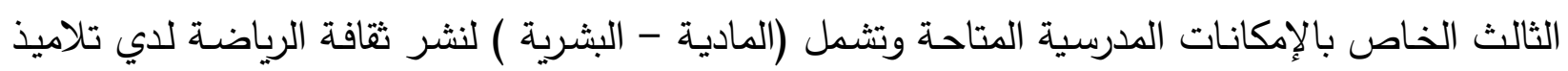
مرحلة التعليم الاساسي للصم البكم : وكانت أعلي نسبة مئويـة في آراء عينة البحث الذين إختاروا (نعم) في العبارة رقم (؟ ) بنسبة

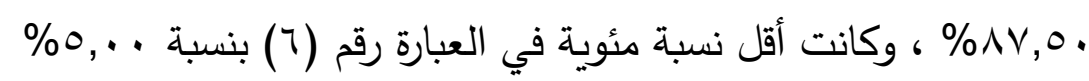

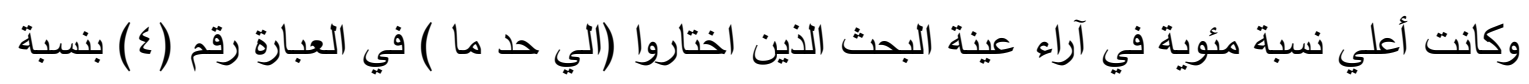

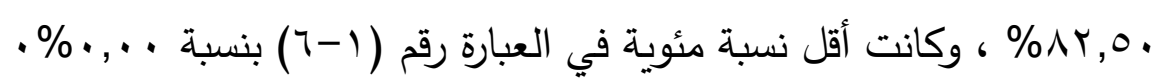

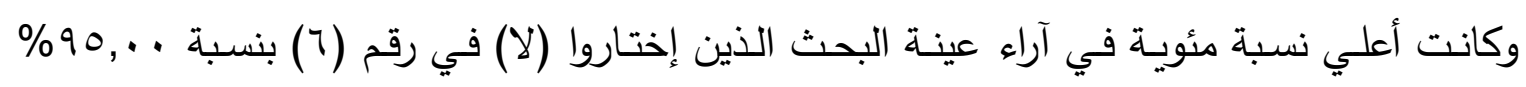

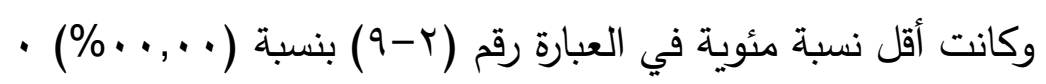

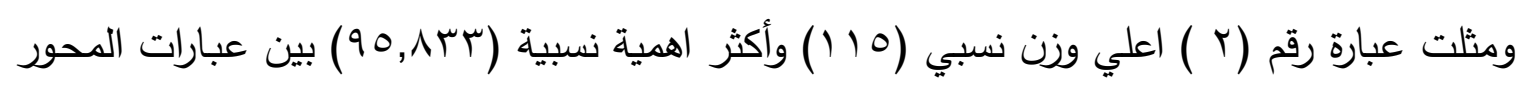

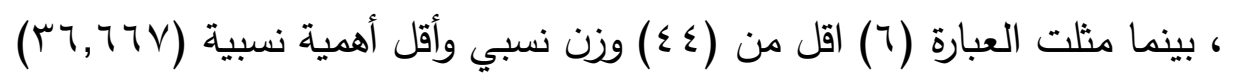

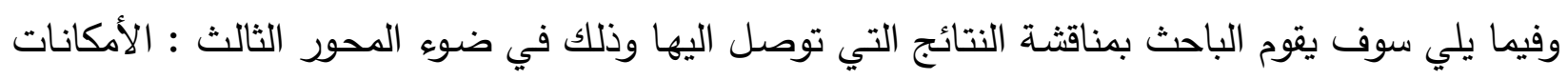
المدرسية المتاحة وتشمل (المادية - البشرية ) لنشر ثقافة الرياضة لدي تلاميذ مرحلة التعليم الاساسي للصح

أشارت نتائج العبارات أرقام (Y-Y- (9-) بالجدول رقم (• (1) أن هناك فروق ذات دلالة معنوية لآراء

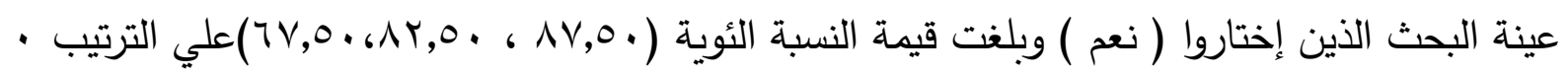

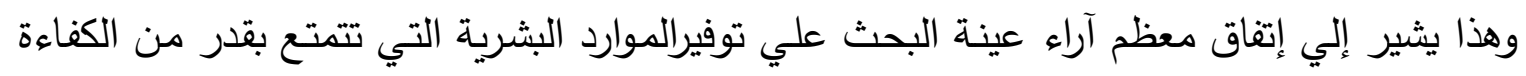

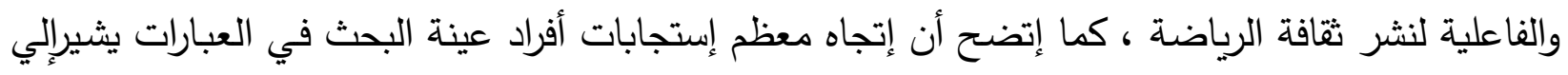

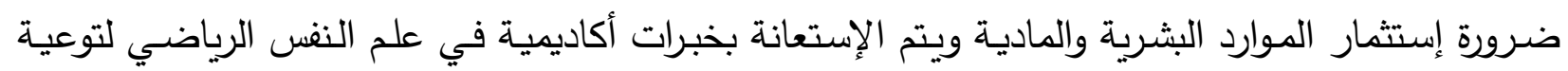

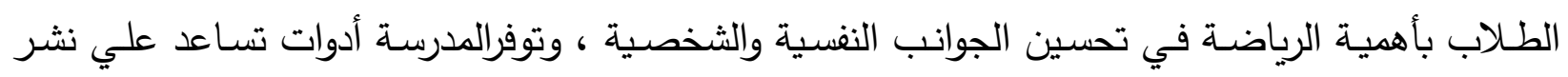

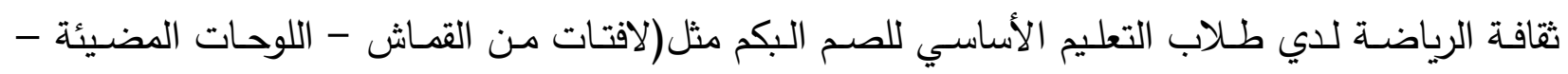
طباعة لافتات - رسم علي الجدران المدرسية لبعض الالعاب ).

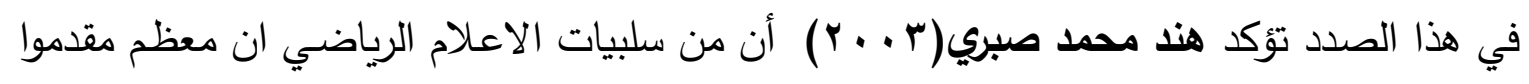

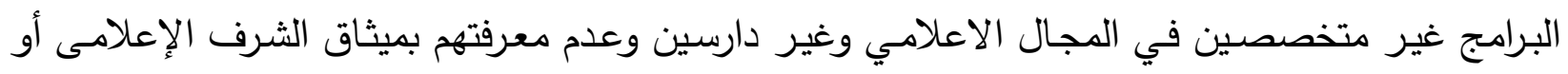

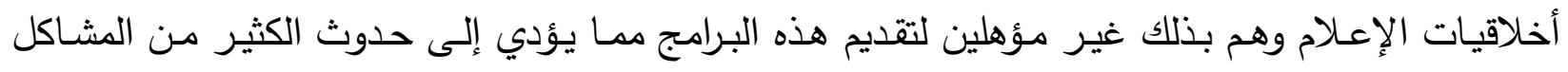
واصبح الإعلام الرياضي في الفترة الأخيرة يعمل على المصالح فقط وزيـادة نسبة المشاهدة وزيادة الربح 


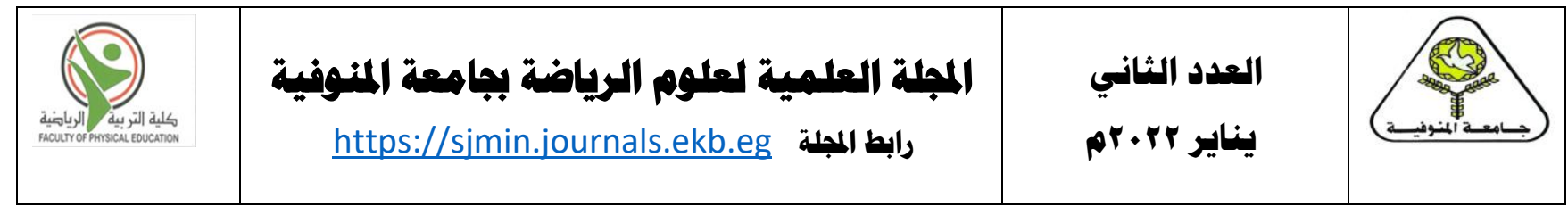

وعدم النظر الى العواقب التي تحدث نتيجة لما يتم تقديمه خلال هذه البرامج حيث عملت هذه البرامج على

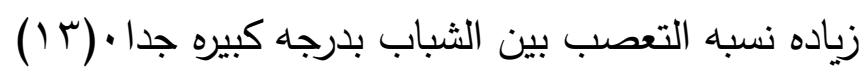

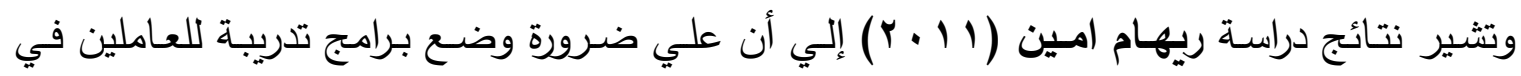

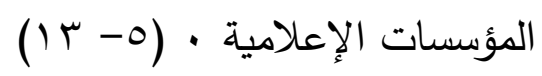

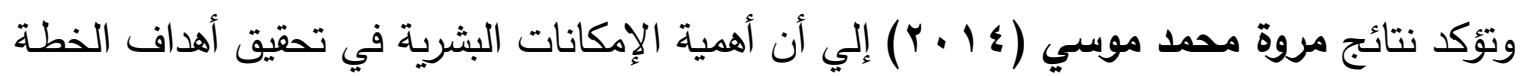

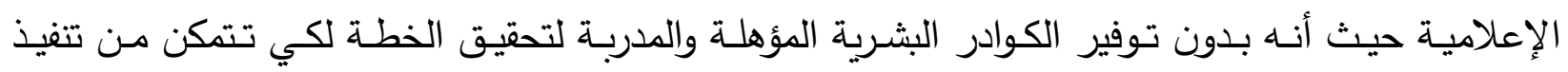
أهدافها ( ) (Y)

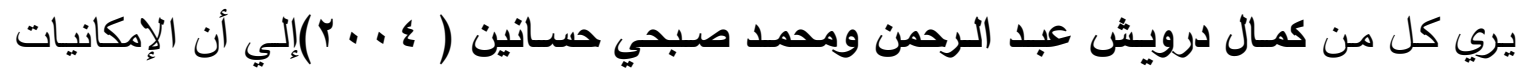
البشرية مثل المديرين والعاملين في المؤسسة وأهميه النوعية من الموارد مسؤوله عن تحقيق أهداف المؤسسة وإبتكار أفكار تؤدي إلى حدوث تغيرات يزيد من معدلات المشتركين في الأنشطة بحيث تقابـل ميولهم

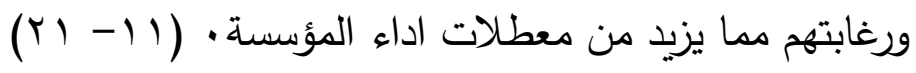

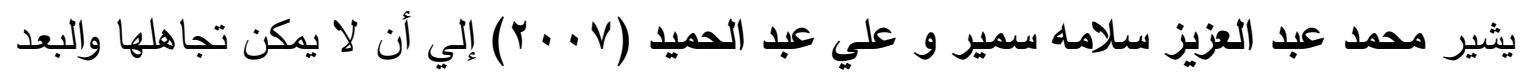

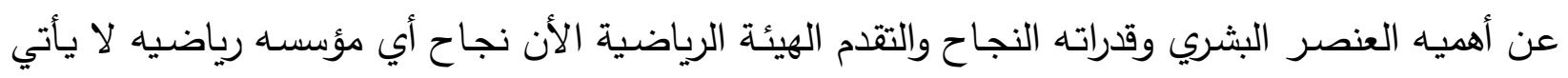
الإعن طريق توفر المدربين المتخصصـين لعمليـه التدريب وكذلك توفيرالجهاز الإداري المؤهل للعمل . $(9 \leq-1 Y)$ كما يشير عادل حرحوش صالح واخرون( ؟ + . ؟ ) أن التدريب وتتمية العاملين لابد أن يكون من خلال الجهد المخطط والمنظم من قبل المنظمة لتزويد العاملين بمعارف معينـة وتحسين وتطوير مهاراتهم

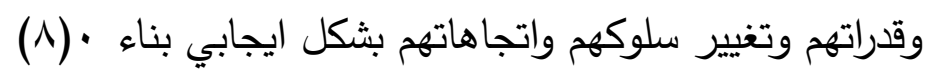

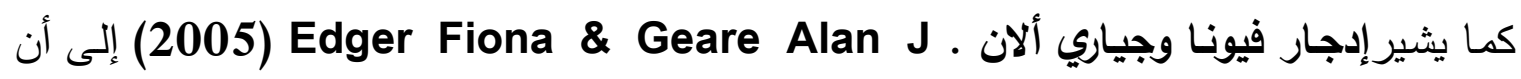
تدريب العامل أو الموظف وتتميته قد أصبحت مسألة مهمة وعلى نحو متزايد ، وأن هناك إرتباط إيجابيا بين

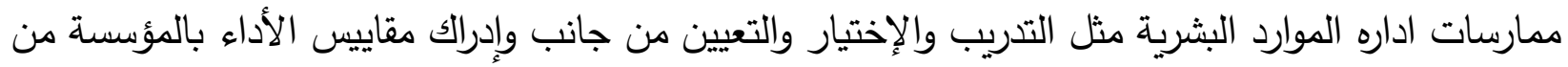
جانب آخر فإن هذه الممارسات تؤثر إيجابيا على الأداء الإبتكاري • (10)

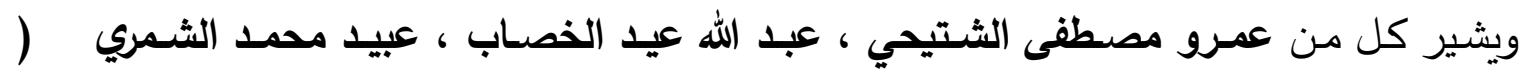

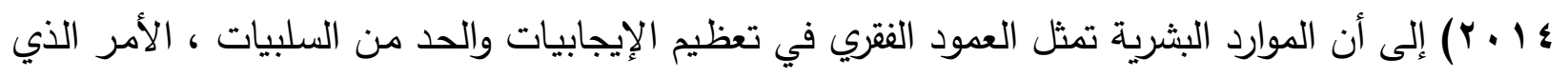

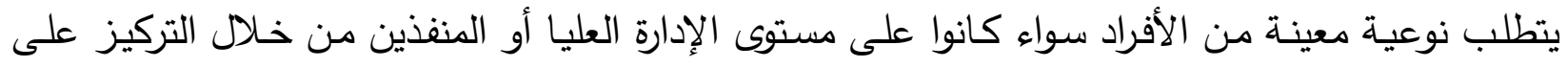

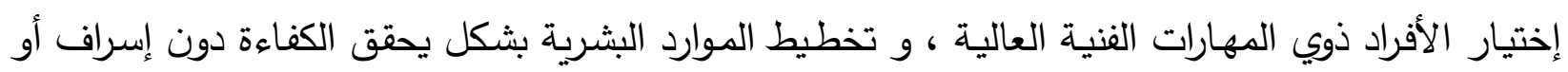




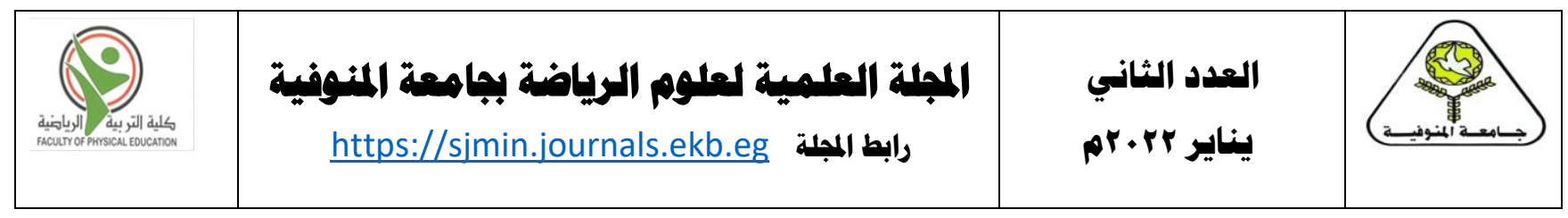

نقص في الموارد البشرية مع تحقيق التكامل بين العناصر الوظيفية ، والسعي إلي إجتذاب العناصر الوظيفية

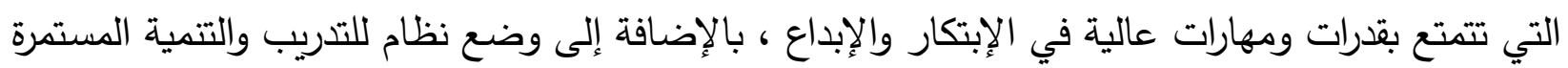

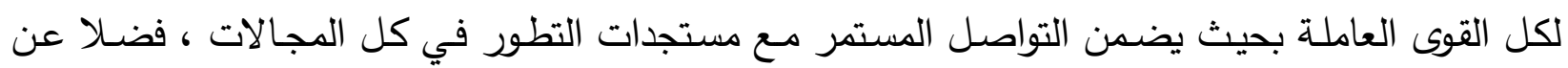

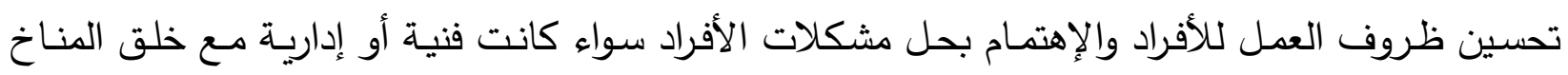

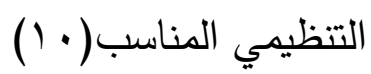

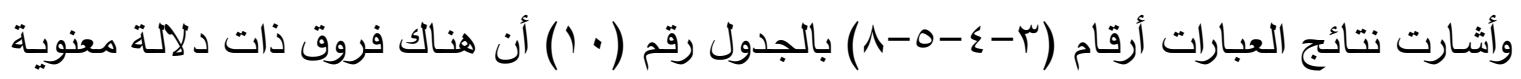

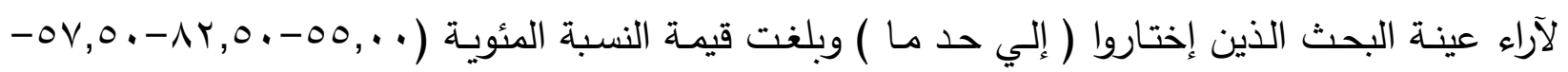
• علي الترتيب (ov,O. وهذا يشير إلي إتفاق معظم آراء عينة البحث إلي حد ما إلي تلقي الموارد البشرية التدريب الجيد

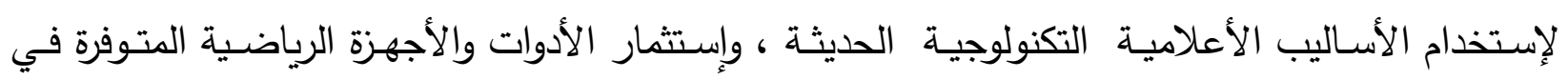

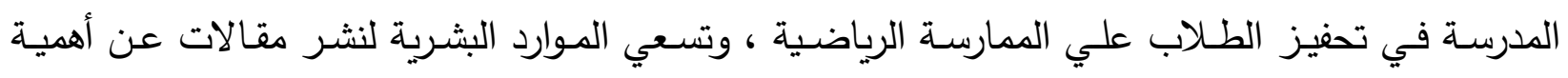

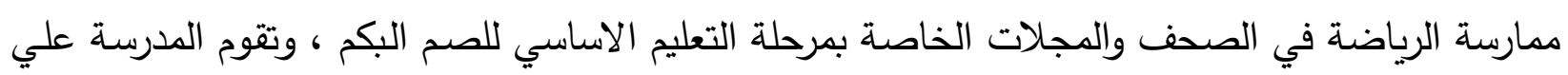
إستقطاب الأجهزة التي تساعد علي نشر الثقافة الرياضية بين طلاب التعليم الاساسي مثل (شاشات التلفاز -

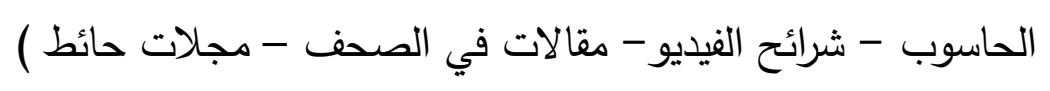

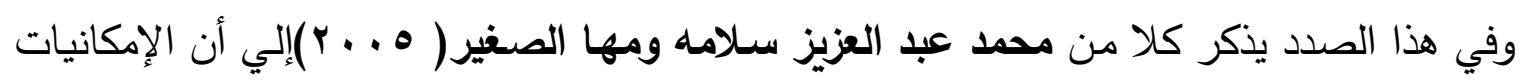

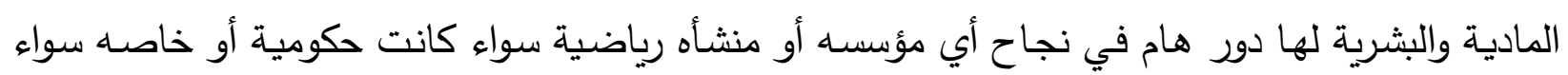

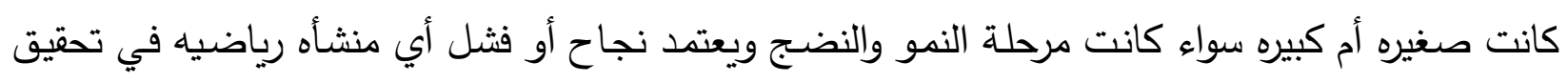

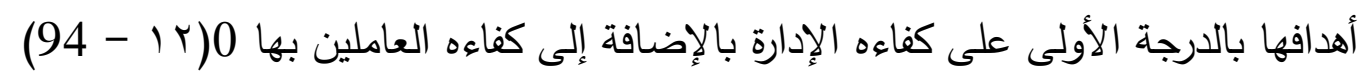

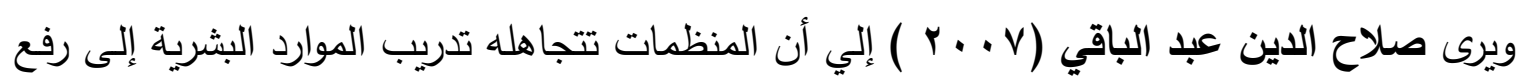

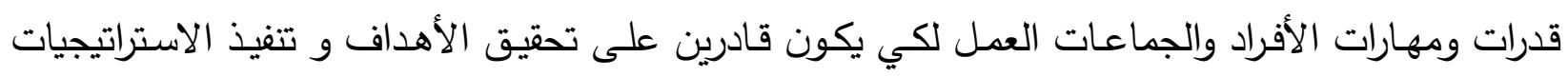

$(22: \vee) 0$

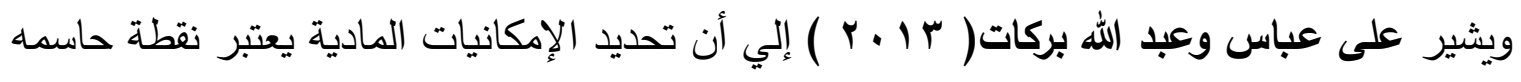

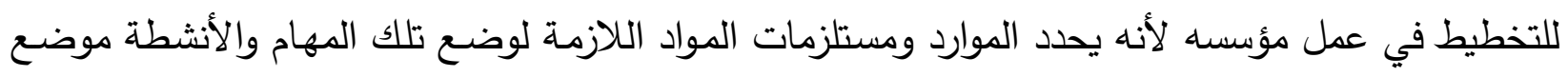

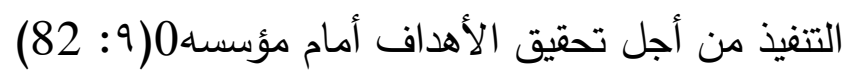




\begin{tabular}{|c|c|c|c|}
\hline (1) & الهبة العلمية لعلوم الرياضة بمامعة المنوفية & اليناير r.r. الثدد الثاني & ويسـة \\
\hline
\end{tabular}

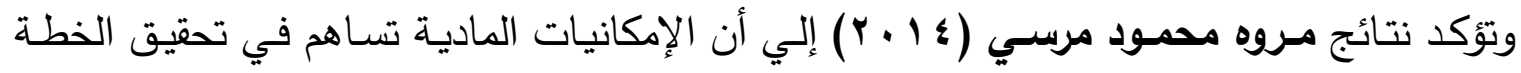

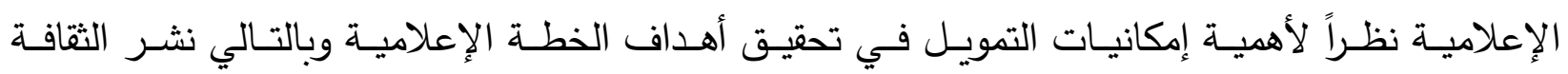

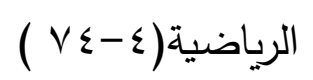

ويري الباحث أن لابد من التدريب الجيد للكوادر البشرية بكافة الأساليب العلمية والإعلامية الحديثة

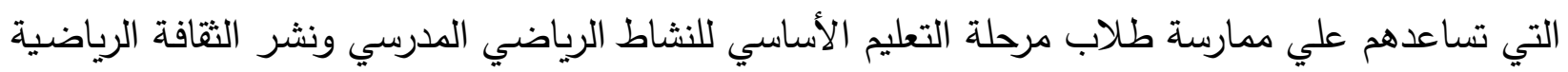

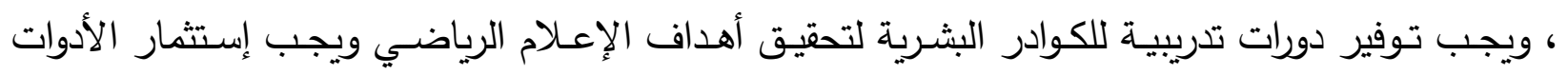

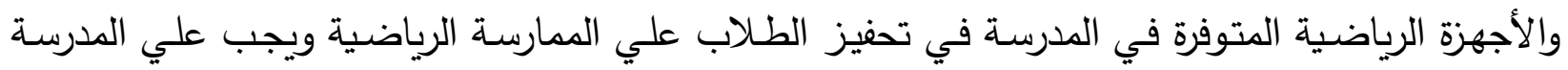

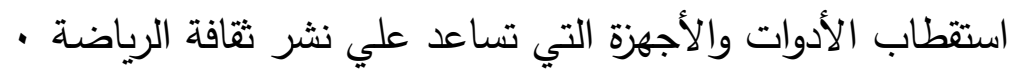

| الإستنتاجات.

1. تكوين الآراء والأتجاهات الإيجابية للطلاب نحو ممارسة الانشطة الرياضية .

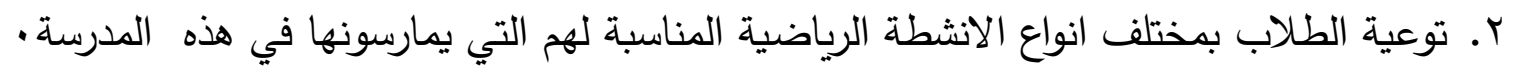

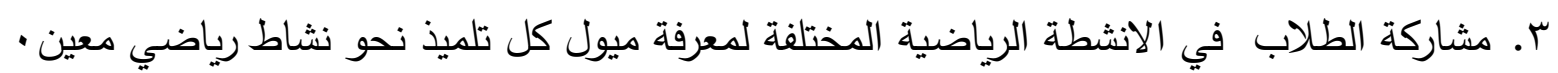

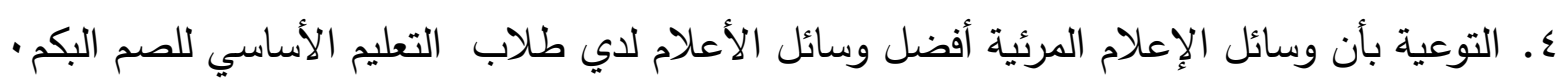
ه. إستخدام المدرسة أجهزة إعلامية حديثة لنشرالثقافة الرياضية مثل (أفلام تسجيلية - الحاسب الإعلئ الآلي ).

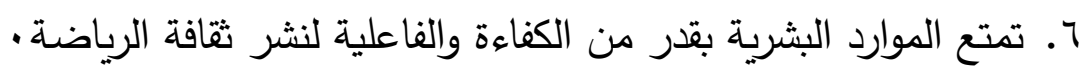

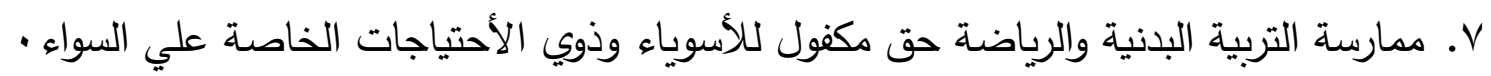
- التوصيات. - -

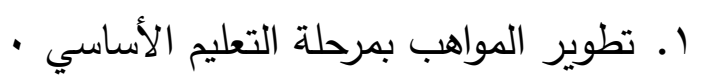

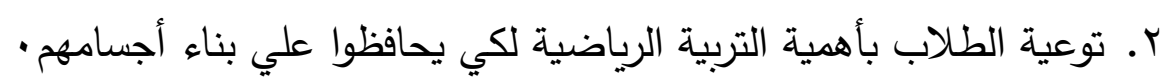

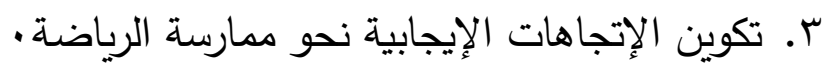

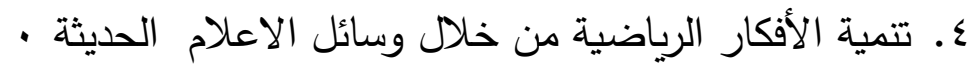

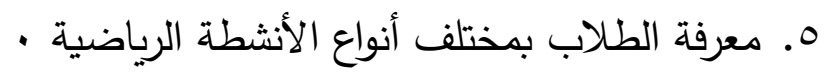

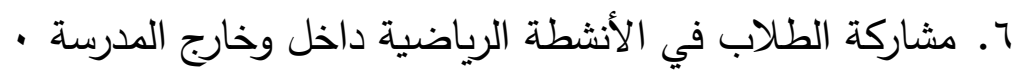

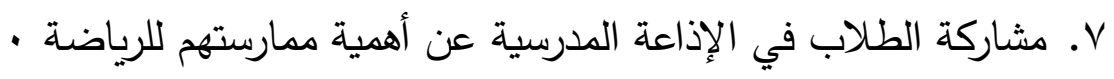

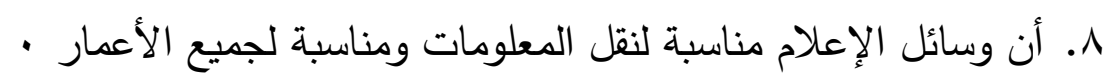




\begin{tabular}{|c|c|c|c|}
\hline (1) & المبلة العلمية لهلوم الرياضة بمامعة المنوفية & 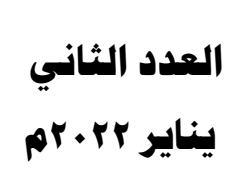 & \\
\hline
\end{tabular}

9. الإبتكار في إختيار وسائل الإعلام الحديثة وتتماشي مع طلاب المرحلة.

- المراجع.

1- ايمن محمد الهناوي: تحليل برامج التليفزيون الرياضية واثرها علي نشر الوعي الرياضي ، رسالة

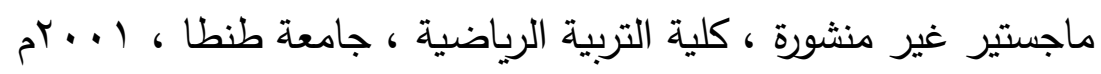

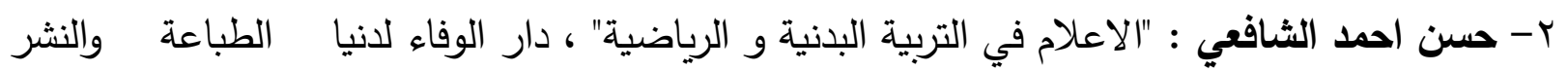

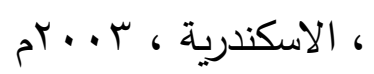

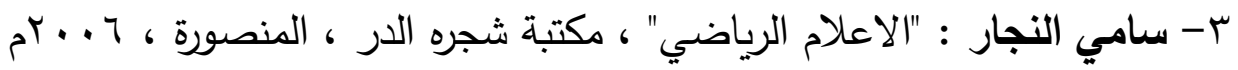

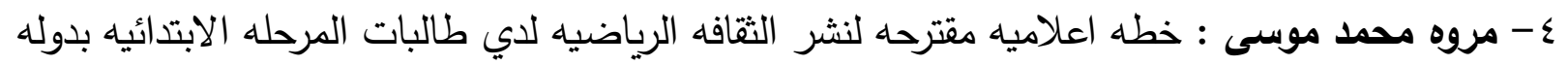

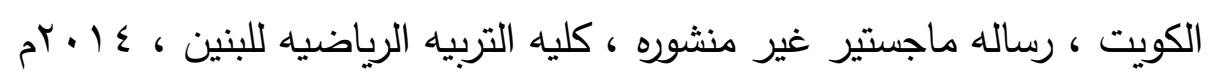

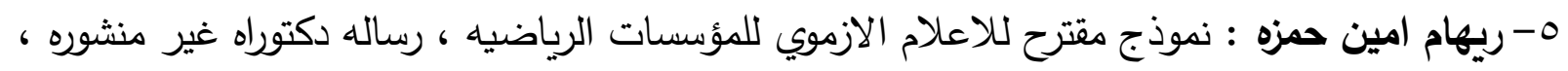

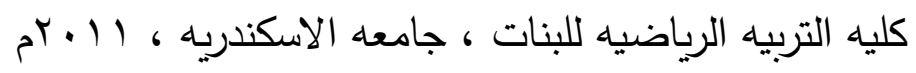

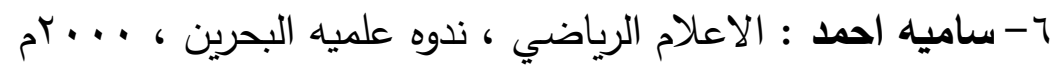

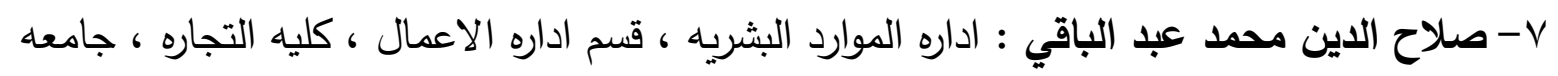

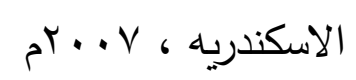

1- عادل حرحوش صالح واخرون : الاداره الاستراتيجيه للموارد البشريه في ظل اعاده الهيكلة ، الاندماج ،

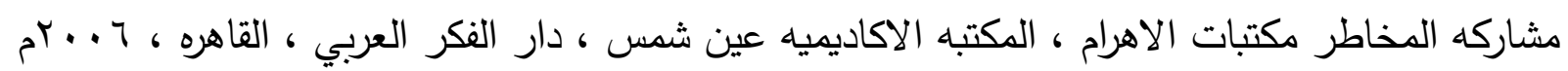

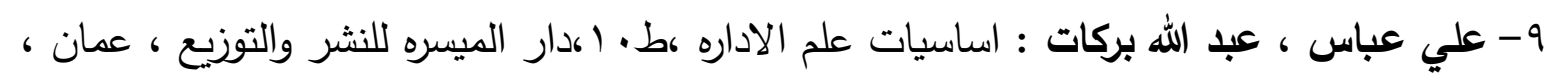

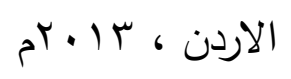

• 1- عمرو مصطفى الثتيحي ، عبد الله عيد الخصاب ، عبيد محمد الثمري : اداره الموارد البشريه

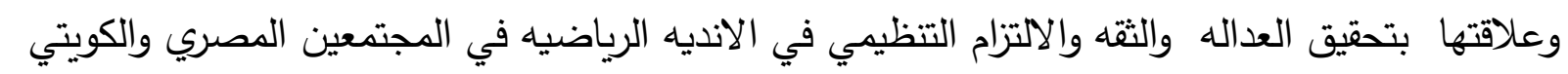

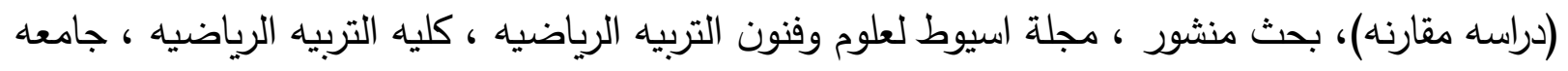

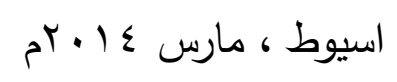

11 - كمال عبد الرحمن درويش ، محمد صبحي حسانين : موسوعه متجهات ادارة الرياضه في مطلع القرن

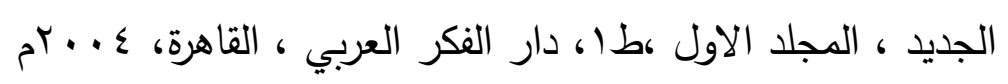




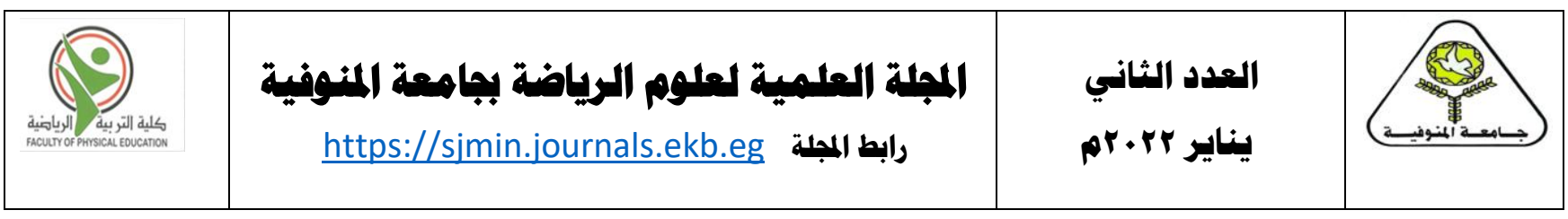

r ا - محمد عبد العزيز سلامه ،مها محمد الصغير : مدخل في الاداره ، الثنهابى للطباعه والنشر ،

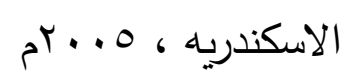

ب ا - هند محمد صبري : علاقه تعرض الثباب المصري للبرامج الرياضيه في القنوات الفضـائية المتخصصه وتاثيرها على الانتماء والتعصب ، رساله ماجستير غير منشوره ، كليه

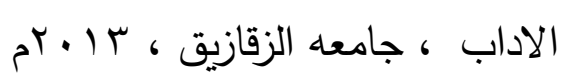

ء ا - مكارم حلمي أبو هرجة ، محمد سعد زغلول : مناهج التربية الرباضبة ، مركز الكتاب

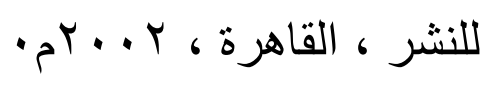

- المراجع الأجنبية.

15-Edgar Fiona \& : Employee Voice Of Human Resource m

Geare AlanJ. Management, Basis Pacific Journal Of Human Resource, Vol. 43,No.3,pp.361-380, 2005. 